\title{
Perspectivas atuais sobre tecidos moles não mineralizados em fósseis de dinossauros não avianos
}

\section{CURRENT PERSPECTIVES ON NON-MINERALIZED SOFT TISSUES IN NON-AVIAN DINOSAUR FOSSILS}

\author{
Everton Fernando Alves ${ }^{1}$, Márcio Fraiberg Machado² \\ 1 - Universidade Estadual de Maringá, Maringá, PR \\ 2 - Departamento de Educação, Faculdade Adventista Paranaense, Ivatuba, PR \\ E-MALL: EVERTONANDO@HOTMALl.COM, PROFMARCIOFRAIBERG@GMALl.com
}

\begin{abstract}
Despite extensive published literature, skepticism about the claim of original soft tissues persists and the subject remains controversial. Data regarding the frequency of soft tissue findings are still scarse and those that have already been systematized are dispersed in the literature, which leads the idea of soft tissues to be associated with isolated phenomena. This article presents a review of the relevant literature, published in the last 50 years, in order to better understand the frequency of non-mineralized soft tissue findings in non-avian dinosaur fossils, and the time limits for expected survival of these biomolecules. The results identified 52 papers describing preserved organic material, considered geologically, geographically and taxonomically comprehensive. Still, it is believed that this frequency is underreported due to the current resistance in accepting these findings as being from organic remnants. The prediction is that acquisition of new technologies will turn such findings as the norm and not the exception
\end{abstract}

Resumo: Dados a respeito da frequência de achados de tecidos moles não mineralizados ainda são escassos e os que já foram sistematizados estão dispersos na literatura, associando a ideia das descobertas a fenômenos isolados. Este artigo apresenta uma revisão da literatura, publicada nos últimos 50 anos, com o objetivo de compreender a frequência de tecidos moles não mineralizados em fósseis de dinossauros não avianos e os atuais limites temporais de sobrevivência esperada dessas biomoléculas. Os resultados identificaram 52 artigos que descrevem material orgânico preservado em fósseis de dinossauros não avianos, considerados geológica, geográfica e taxonomicamente abrangentes nas rochas mesozoicas. Ainda assim, acredita-se que a frequência é subnotificada devido à atual resistência em aceitar as descobertas como sendo de remanescentes orgânicos e à falta de recursos para esse tipo de detecção. A partir do desenvolvimento de novas tecnologias pode-se prever que tais achados provavelmente serão a norma e não a exceção.
Citation/Citação: Alves, E. F., \& Machado, M. F. (2020). Perspectivas atuais sobre tecidos moles não mineralizados em fósseis de dinossauros não avianos. Terræ Didatica, 16, 1-14, e020028. doi: 10.20396/td.v16i0.8659539

Keywords: Molecular paleontology. Exceptional preservation. Organic molecules. Mesozoic.

Palavras-chave: Paleontologia molecular. Preservação excepcional. Moléculas orgânicas. Mesozoico.

Manuscript/Manuscrito:

Received/Recebido: 13/05/2020

Revised/Corrigido: 11/06/2020

Accepted/Aceito: 19/06/2020

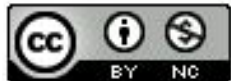

\section{Introdução}

No passado, paleontólogos pensavam serem raros os achados de tecidos moles ou tecidos não resistentes, como também é conhecido o termo (Allison \& Briggs, 1993, Benton, 1998, Gobbo \& Bertini, 2015). Porém, o tempo mostrou que eles são mais comuns do que se pensava (Schweitzer et al., 2007a, Schweitzer et al., 2007b, Edwards et al., 2014, Bertazzo et al., 2015). Tafônomos e paleobiólogos nos últimos 20 anos têm voltado sua atenção para o estudo desse processo de preservação observado no registro fóssil, que eles chamam de soft tissue (termo em inglês), sem, contudo, corretamente defini-lo.

Tecidos moles são estruturas teciduais, moléculas orgânicas ou seus fragmentos alterados que não sejam tecidos duros, ou biomineralizados, de um organismo - como ossos, dentes, vértebras, conchas, lenhos, sementes, carapaças (Gobbo \& Ber- tini, 2015). No geral, o termo tecido mole é usado em oposição às partes duras.

O registro fóssil é diverso e têm sido encontrados em excepcional estado de conservação organismos animais (vertebrados e invertebrados) e vegetais (vasculares ou avasculares) com partes moles, isto é, com poucas partes duras (Thomas \& Taylor, 2019). Existem várias localidades no planeta consideradas Konservat-Lagerstätten, ou seja, depósitos sedimentares excepcionais pela qualidade incomum na preservação de tecidos moles sejam na forma de moldes e impressões, como nos fósseis do Folhelho de Burgess, ou mesmo de substituição por minerais autigênicos como, por exemplo, dos fósseis da Formação Santana, na Bacia do Araripe (Allison, 1988, Briggs et al., 1997, Gobbo \& Bertini, 2015, Mcnamara et al., 2018).

No geral, podem-se considerar três os tipos 
(estados) de tecidos moles que ocorrem no registro fóssil. O primeiro diz respeito ao tecido mole mineralizado, ou seja, tecido mole totalmente substituído por minerais (Carvalho, 2010). Para esse tipo de tecido mole, a ação microbiana tem sido apresentada como um dos fatores responsáveis pela excelente preservação de ultraestruturas por atuar como indutor da substituição autigênica de partes moles e como selante natural dos restos orgânicos frente aos processos tafonômicos, retardando sua taxa de degradação. O segundo tipo está relacionado ao tecido mole parcialmente substituído por minerais. O terceiro é o tecido mole não mineralizado, isto é, caso em que o tecido mole original de alguma forma não foi substituído por minerais durante a fossildiagênese.

Fossildiagênese são os processos tafonômicos físico-químicos que atuam sobre os restos orgânicos de um organismo após o soterramento, desde a sua morte até a sua completa fossilização (Fernandes, 2020). Durante esse processo, a sequência esperada para a etapa de decomposição de um organismo é que os tecidos moles sejam os primeiros a serem afetados, a não ser que algum fenômeno interrompa a decomposição e permita uma mineralização diagenética precoce (Gobbo \& Bertini, 2015). Por mineralização diagenética entende-se a precipitação de minerais autigênicos durante o processo de diagênese (formação) das rochas. Minerais autigênicos, por sua vez, são grupo de minerais formados durante a sedimentação ou na fase de diagênese precoce no próprio lugar em que estão situadas.

Nos últimos 20 anos descobriu-se que a preservação excepcional - que se caracteriza pelo alto grau de preservação de detalhes das características histológicas e anatômicas - de tecidos moles tanto daqueles mineralizados quanto dos não mineralizados, que antes se pensava atingir o nível celular, igualmente afeta ao nível molecular.

Existe grande diversidade de tecidos moles não mineralizados - também conhecidos como moléculas orgânicas ou biomoléculas endógenas (originais) - que são encontrados em fósseis, desde remanescentes bioquímicos, proteínas e pigmentos extracelulares, proteínas citoesqueléticas, compostos no interior das células quimicamente consistentes com o DNA e dados de sequências peptídicas, incluindo proteínas histonas (Bailleul et al., 2020).

Investigações sobre o estado da arte a respeito de tecidos moles não mineralizados possuem importância prática direta na Paleontologia do século XXI. As descobertas abrem um leque de novas possibilidades no campo e fornecem insights sobre a natureza e a biologia, dentre outros aspectos, de animais extintos, mais especificamente acerca da fisiologia, comportamento, dieta, diagênese e da sistemática, especialmente dos dinossauros não avianos (Bertazzo et al., 2015, Wiemann et al., 2018).

Os dinossauros não avianos são parte de um clado maior de répteis, os Archosauria, dos quais existem apenas duas linhagens sobreviventes, crocodilianos e aves (Bailleul et al., 2019). Nesse sentido, dados de tecidos moles não mineralizados em dinossauros não avianos podem ser utilizados para análises filogenéticas, inferências ecológicas e para reconstruir a fisiologia dos animais, além de permitir que novas gerações de pesquisadores conheçam mais a fossildiagênese. Contudo, dados sobre frequência de achados de tecidos moles ainda são escassos; os que já foram sistematizados estão dispersos na literatura, o que faz com que tecidos moles não mineralizados em dinossauros não avianos sejam associados a fenômenos isolados.

Assim sendo, o objetivo geral desta pesquisa é revisar a literatura publicada nas últimas cinco décadas, a fim de compreender melhor a frequência dos achados de tecidos moles não mineralizados em fósseis de dinossauros não avianos, e a previsão a respeito dos limites temporais atuais de sobrevivência dessas biomoléculas.

\section{Biomoléculas originais: a regra ou a exceção?}

Tecidos moles originais não são encontrados apenas em estratos da Era Mesozoica (251-65,5 $\mathrm{Ma}$ ), pois sua presença ocorre ao longo do registro geológico (Thomas \& Taylor, 2019), como por exemplo, em camadas bem mais antigas, tais como as dos períodos Devoniano (417 Ma; Cody et al., 2011), Ordoviciano ( $\pm 480 \mathrm{Ma}$; Towe \& Urbanek, 1972), Cambriano (época Miaolingiano, $505 \mathrm{Ma}$; Ehrlich et et al., 2013), e das Eras Neoproterozoico (período Ediacarano, 571-541 Ma; Moczydłowska et al., 2014, Bobrovskiy et al., 2018) e até mesmo do Paleoproterozoico (1,1 Ga; Alleon et al., 2016).

Os descritores "tecido mole" e "preservação de tecido mole" são mencionados na literatura paleontológica, e, em muitos casos, os autores desses estudos buscam transmitir a ideia de tecido mineralizado (Thomas \& Taylor, 2019). Porém, várias publicações científicas nas últimas décadas 
indicaram um aumento nas descobertas de tecidos moles não mineralizados (Schweitzer et al., 2007a, Schweitzer et al., 2007b, Schweitzer et al., 2009).

Segundo Edwards et al. (2014, p.685), “até agora os dados mostram que a retenção química original pode ser mais comum do que se pensava anteriormente". Em 2019, um estudo revisou a literatura e encontrou 88 publicações com achados de tecidos moles em variados táxons de animais e de vegetais nas últimas décadas, com aumento considerável nos últimos dez anos (Thomas \& Taylor, 2019). Os autores concluíram que tecidos moles não mineralizados é geologicamente extenso, geograficamente global e taxonomicamente abrangente. Atualmente, o número já ultrapassou 110 artigos (Thomas \& Enyart, 2020).

Por outro lado, apesar de um vasto conjunto de pesquisas relatarem tais achados, o ceticismo em relação à reivindicação de material orgânico original persiste e o assunto ainda hoje permanece controverso (Briggs et al., 1997, Buckley et al., 2008, Kaye et al., 2008, Pevzner et al., 2008, Bern, 2009, Buckley et al., 2017, Thomas \& Taylor, 2019, Saitta et al., 2019, Liang et al., 2020). Mais especificamente em relação aos dinossauros não avianos, outra pesquisa avaliou amostras fósseis de oito indivíduos e relatou tecidos não mineralizados em seis espécies (Bertazzo et al., 2015).

Assim, procurou-se efetuar uma revisão narrativa dos artigos que abordam os descritores "paleontologia molecular"; "dinossauros"; "tecidos moles"; "preservação excepcional”; "moléculas orgânicas"; tanto em língua portuguesa quanto em inglês. Essa busca, com os termos em conjunto e logo após, separados, foi realizada em revistas revisadas por pares e ocorreu no intervalo de tempo compreendido entre 1966 a 2020, nas plataformas PubMed, SciELO e CAPES. Na ausência de achados com a temática, ampliou-se o espectro de busca para o Google acadêmico. A busca resultou em uma lista detalhada das publicações com achados de tecidos moles não mineralizados em fósseis mesozoicos de dinossauros não avianos. Na Tabela Suplementar 1 (ver Material Suplementar), foram rejeitados os artigos que identificaram apenas casos de tecidos moles mineralizados (substituição total por minerais autigênicos), artigos que identificaram tecidos originais de partes duras (e.g. biominerais endógenos de ossos), artigos que identificaram tecidos moles não mineralizados em dinossauros avianos, bem como aqueles artigos que identificaram tecidos moles, porém não apresentaram informações detalhadas para as variáveis selecionadas na construção da tabela.

Algumas das primeiras descobertas remonta à década de 1960, quando foram encontradas fibras da proteína colágeno, osteócitos e vasos sanguíneos em fósseis de dinossauros não avianos (Isaacs et al., 1963, Pawlicki et al., 1966). Ademais, o registro de tecidos moles cobre todos os períodos da Era Mesozoica, sendo o caso mais antigo a ocorrência de colágeno encontrado em um dinossauro prossaurópode datado do Triássico Superior (Isaacs et al., 1963).

O resultado da busca (Tabela Suplementar 1) apresenta algumas tendências que sugerem questões de pesquisa para futuras investigações. A primeira tendência revela de forma preliminar uma distribuição geográfica ampla no globo terrestre, de tecidos moles não mineralizados de dinossauros não avianos, nos continentes norte-americano, sul-americano, europeu, asiático e africano, especificamente nos estratos com dinossauros não avianos. Os locais descritos na Tabela Suplementar 1 (ver Material Suplementar) sugerem pesquisas futuras na extensão de sua cobertura. Os dados atuais parecem insuficientes para responder isso. No entanto, a ausência de cobertura em algumas regiões pode significar simplesmente que os pesquisadores ainda não procuraram ou não possuem as ferramentas para este tipo de deteç̧ão.

A segunda tendência indica que os táxons de dinossauros contendo dados bioquímicos de tecidos moles não mineralizados variam amplamente, sendo distribuídos nas duas grandes ordens do clado Dinosauria. Em relação à ordem Saurischia, este trabalho encontrou relatos de tecidos moles não mineralizados em representantes de nove famílias diferentes da subordem Theropoda e em três distintas famílias da subordem Sauropodomorpha. Para a ordem Ornithischia, os resultados indicaram registros de tecidos moles não mineralizados em representantes de três famílias da subordem Thyreophora, em duas famílias da subordem Ankylosauria, em duas famílias da subordem Marginocephalia, em duas famílias da subordem Ornithopoda e em uma família para a subordem Cerapoda.

Para tecidos moles mineralizados, a literatura relata que o clado dos hadrossaurídeos exibe globalmente mais achados de tecidos moles de pele do que qualquer outro grande clado de dinossauro (Davis, 2014); com 31 vezes mais chances de preservar a pele do que os restos de outros dinossauros, o que faz com que a pele dos hadrossauros pareça ter resistência ao decaimento orgânico (Davis, 2014, 
Fabbri et al., 2020). A razão pela qual tantos fósseis de hadrossaurídeos preservaram a estrutura da pele ainda é desconhecida, com a possibilidade de ser algo intrínseco ao táxon (Davis, 2014), ou a um viés tafonômico do ambiente de deposição.

A terceira tendência revela um crescente interesse nos últimos anos na investigação de tecidos moles não mineralizados em dinossauros não avianos. Porém, é válido enfatizar que embora frequente, acredita-se que esses numeros estejam subnotificados devido à resistência que ainda hoje persiste na comunidade paleontológica em aceitar esses achados como verídicos (Schweitzer et al., 2007a). Observa-se que os fósseis não têm sido suficientemente explorados em busca de tecidos moles, e investigações a níveis moleculares têm sido ignoradas nas últimas décadas, o que faz com que os dados reais fiquem encobertos (Schweitzer, 2011).

Aliás, acredita-se que, devido a isso, a paleontologia tenha demorado a se desenvolver e adotar novas metodologias (van der Reest \& Currie, 2020). As tecnologias atuais também têm sido apontadas em estudos recentes como inadequadas para a identificação de maior volume de amostras de tecidos moles não mineralizados em fósseis de dinossauros não avianos (Thomas \& Taylor, 2019), porque a maioria das metodologias utilizadas não apresentam um teste padronizado e amplamente acessível para confirmar todos os tipos de tecidos moles não mineralizados em fósseis, algumas não apresentam sensibilidade a determinadas biomoléculas e várias delas são parcial ou totalmente destrutivas para a amostra.

Ainda assim, os resultados publicados sugerem duas hipóteses. Primeiro, novas tecnologias surgirão e continuarão identificando tecidos moles não mineralizados em novos lugares. Segundo, as faixas geográficas e estratigráficas contendo essas biomoléculas continuarão a aumentar.

\section{A problemática do tempo de decaimento de biomoléculas}

O processo diagenético das rochas pode ser dividido em três fases: Eodiagênese, que se configura como um estágio precoce da diagênese e que ocorre próximo à superfície de sedimentação, em temperaturas e pressões baixas (entre $30^{\circ} \mathrm{C} \mathrm{e} 70^{\circ} \mathrm{C}$ ); a Mesodiagênese que ocorre no pós-soterramento, em profundidades de quilômetros, sob alta pressão e temperatura; e a Telodiagênese que ocorre após uma inversão tectônica, com o soerguimento das rochas sedimentares e o retorno destas à superfície. Esses processos físico-químicos que agem sobre as camadas sedimentares afetam também os restos orgânicos, que sofrem uma série de processos de transformação, chamados de fossilização (Fernandes, 2020).

Sabe-se que os processos eodiagenéticos, em especial, a eodiagênese dos bioclastos - fragmentos fósseis esqueléticos de organismos marinhos ou terrestres - que ocorre na interface água-sedimento tendem a obstruir total ou parcial os poros das camadas sedimentares devido à cimentação, e dessa forma retardam a taxa de decomposição do material orgânico de fósseis presentes nas camadas sedimentares (Carvalho, 2010, Fernandes, 2020).

Ademais, a preservação excepcional dos fósseis tem sido explicada por alguns fatores abióticos, a exemplo do rápido soterramento após a morte, anoxia ou desoxia, $\mathrm{pH}$, ausência de decomposição bacteriológica, composição química e estrutural do esqueleto, hipersalinidade, modo de vida e condições químicas que imperam no meio (Carvalho, 2010, Gobbo \& Bertini, 2015). Por exemplo, águas ricas em cálcio neutralizam os ácidos dentro dos sedimentos, permitindo que partes moles de vertebrados permaneçam intactas. Em determinados ambientes, como o marinho, por exemplo, alguns autores têm considerado a presença de um fator biótico, esteiras microbianas, depositadas junto ao fundo, que seria importante para a preservação das partes moles, por promover a rápida mineralização dos tecidos.

Geralmente, os fósseis com partes duras ou biomineralizadas (ossos, dentes, conchas e carapaças) são mais comumente preservados por permineralização e por substituição (Carvalho, 2010). Por sua vez, partes moles são preservadas por fosfatização, sulfurização, piritização ou querogenização, além de preservação por silicificação, carbonização, preenchimento por filossilicatos ou permineralização por apatita (Edwards et al., 2011). Exceto pela querogenização e carbonização, esses modos descrevem minerais que substituem o tecido original. Além disso, há casos de tecidos moles originais preservados parcial ou totalmente por mumificação, como no caso de dinossauros aprisionados em âmbar (Xing et al., 2020) ou em gelo como, por exemplo, mamutes congelados no permafrost da Sibéria (Yamagata et al., 2019).

O fato intrigante é que nos últimos anos tornou-se cada vez mais evidente estruturas teciduais originais como pele, músculos e vasos sanguíneos, 
e mesmo achados mais intrigantes, relacionados à biomoléculas como proteínas e DNA sendo preservados sem mineralização. Essa questão é interessante, pois, imediatamente após a morte, é esperado que os organismos se decomponham rapidamente devido a ação de seres necrófagos e organismos decompositores como bactérias. Esse processo é chamado de necrólise.

A necrólise, porém ocorre de maneira diversa. Experimentos com vertebrados têm demonstrado que, em ambientes aquáticos, a decomposição ocorre de poucos dias a semanas após a sua morte (Elder \& Smith, 1988, Brand et al., 2003a, Anderson \& Bell, 2016). De igual modo, em ambientes terrestres, a decomposição ocorre entre dias a semanas (Brand et al., 2003a, Brand et al., 2003b). No entanto, quando a fossilização ocorre,

"Biocomponentes orgânicos de animais se decompõem e se degradam durante o processo de fossilização, e minerais presentes nas águas subterrâneas penetram e se depositam nos espaços intersticiais dos ossos e dentes de vertebrados, transformando-os lentamente em 'rocha' inorgânica. Em alguns fósseis excepcionalmente preservados, nos quais o processo de decaimento pode ter sido interrompido suficientemente cedo no processo de fossilização, pode ocorrer alguma preservação de tecidos moles porque eles foram isolados do ambiente externo, cimentados e protegidos pelo ambiente inorgânico e não foram completamente permineralizados" (Lee et al., 2017, p.2).

Para os paleontólogos Gobbo e Bertini,

de maneira geral, considerando apenas a composição química original dos organismos, os modelos demonstram que a presença de partes resistentes favorece a fossilização [...]. Os tecidos não resistentes, em geral, são muito susceptíveis à decomposição e excepcionalmente se preservam (2015, p. 4).

O fato de paleontólogos ainda hoje pensarem que descobertas de tecidos moles não mineralizados são raros (Parry et al., 2018) se deve, possivelmente ao desconhecimento acerca dos dados recentes e dispersos sobre esses achados, à falta de interesse ou à impossibilidade de fazer pesquisas na área por conta de não ter acesso a recursos, equipamentos adequados e laboratórios especializados que façam esses tipos de análises. Em algum grau, parece que essa percepção também deriva do fato de que os processos tafonômicos extrínsecos (e.g. ambiente de deposição) e intrínsecos (e.g. potencial de preservação do organismo), que favorecem a preservação de biomoléculas em tempo profundo envolvem uma complexa interação de processos geológicos, químicos e biológicos, sendo ainda hoje pouco compreendidos (Parry et al., 2018, Fabbri et al., 2020). Conforme afirmam Schweitzer e colaboradores,

"Preservar os fósseis de maneira excepcional requer a cessação precoce dos processos de decomposição, sendo atribuível a condições físicas e químicas incomuns, da morte à diagênese, e alteração mínima do material fóssil nos níveis macro e microscópico. Isso, por sua vez, está correlacionado com a preservação de biomoléculas endógenas, fragmentos de moléculas ou biomarcadores (isto é, fragmentos moleculares alterados que podem ser rastreados até a fonte original)" (2005b, p. 780).

Collins e colaboradores admitem que "a deterioração biomolecular ainda permanece um aspecto amplamente inexplorado da diagênese óssea" (2002, p. 386). A literatura científica apresenta diversos experimentos de decaimento de biomoléculas na tentativa de identificar os limites de tempo de sobrevivência delas em relação a variáveis ambientais como umidade, temperatura, oxigênio e pH (Buckley et al., 2011, Allentoft et al., 2012, Orlando et al., 2013).

Sabe-se, até o presente, que os tecidos moles não mineralizados representam desafios únicos ao fluxo de trabalho molecular, visto que tais componentes moleculares originais possuem baixo potencial de preservação. Portanto, aparentemente não poderiam persistir durante enormes intervalos de tempo (Eglinton \& Logan, 1991, Schweitzer et al., 2009, Wadsworth \& Buckley, 2014, Liang et al., 2020).

Diante desse desafio, diversos critérios já foram estabelecidos ao longo dos anos a fim de comprovar a endogeneidade de tecidos moles (Schweitzer, 2011). Mais recentemente, Schweitzer et al. (2019) publicaram uma revisão da paleoproteômica de dinossauros e outros fósseis mesozoicos, fornecendo uma discussão mais recente e sugerindo critérios ainda mais seguros de avaliação da presença de biomoléculas originais em fósseis da Era Mesozoica.

\section{Proteínas}

Observações laboratoriais sugerem que, após a deposição, qualquer colágeno ósseo que escapa

\begin{tabular}{c|c|c|c|c|c}
\hline (C) Terrae Didat. & Campinas, SP & v.16 & $1-14$ & e 020028 & 2020 \\
\hline \multicolumn{2}{|c|}{5}
\end{tabular}


da biodegradação decai rapidamente nas primeiras semanas e depois diminui para um regime de decaimento mais linear (Dobberstein et al., 2009). Tais estudos modelam a deterioração do colágeno ósseo em tempo arqueológico - isto é, escala de tempo relativa à presença de vestígios materiais da existência humana ou dos primeiros hominídeos - usando condições ideais, como pH quase neutro, quase esterilidade e hidratação constante.

Por outro lado, a previsão é de que o osso fóssil em tempo geológico (profundo) geralmente não retém colágeno suficiente para retransmitir informações biológicas. É esperado que dentro de algumas centenas de milhares a um milhão de anos, todas as proteínas nas estruturas de tecidos moles devem ser hidrolisadas e completamente degradadas (Tab. 1).

\section{Material genético}

Até o momento, é consenso na academia (Tab. 1) que material genético não persiste em tempo profundo. A existência de DNA de 65 milhões de anos, por exemplo, é bioquimicamente impensável. Isso porque logo após a morte, o DNA começa a decair. Estudo publicado em 2012 demonstrou que o DNA se deteriora numa taxa tão alta que ele perde metade de seu conteúdo original a cada 521 anos (Allentoft et al., 2012). Com essa velocidade de deterioração, pesquisadores só poderiam recuperar sequências de DNA de no máximo 6,8 milhões de anos. Ademais, as ligações químicas em uma fita de DNA vão sendo perdidas e, assim, o DNA deixa de ser legível muito antes, em cerca de 1 milhão de anos, quando as sequências restantes seriam muito curtas para fornecer informações significativas.

Paleontólogos moleculares tendem a ignorar fragmentos com menos de 30 pares de bases, uma vez que pequenas sequências de material genético não contêm informações suficientes para serem replicadas (Greshko, 2020). A mais antiga sequência de DNA original em quantidade significativa extraída de núcleos de gelo foi datada de cerca de 700 mil anos (Willerslev et al., 2007). Outro ponto de discussão recente se concentra em torno de relato de possível DNA de bactérias dentro de ossos fósseis de um representante de dinossauro não aviano do gênero Centrosaurus (Liang et al., 2020).

Casos como estes dificultam as análises paleomoleculares, pois será necessário considerar a possibilidade de que esteiras microbianas compostas por comunidades diversas de bactérias con- seguissem se instalar dentro dos ossos a ponto de produzir substância extracelular polimérica (EPS) que pudesse ser confundida com tecidos moles, especialmente tecidos semelhantes à núcleos celulares e material genético como DNA de dinossauros (Black, 2020).

Pesquisas têm sugerido o uso de datação por radiocarbono como potencial estratégia para confirmar a origem de contaminação relativamente moderna por biofilmes bacterianos que supostamente imitariam vasos sanguíneos e osteócitos reais (Kaye et al., 2008). Porém, essa proposta tem sido considerada fraca (Zimmer, 2008) porque a datação por radiocarbono detecta elementos de até 60 mil anos, logo, não conseguiria detectar contaminações ainda mais antigas.

Para conhecer os atuais limites temporais de sobrevivência de biomoléculas originais que compõem os tecidos moles como, por exemplo, o DNA as pesquisas baseiam-se em cinética teórica e experimentos de laboratório projetados para simular a diagênese dos biomateriais através da exposição a condições adversas (por exemplo, baixo $\mathrm{pH}$ e alta temperatura) e prever a degradação completa de biomoléculas mensuráveis em taxas simuladas (Buckley et al., 2011, San Antonio et al., 2011, Alleon et al., 2017, Boatman et al., 2019).

Quanto aos resultados desses experimentos relativos ao tempo de sobrevivência de fragmentos moleculares, os dados até então disponíveis na literatura científica puderam ser coletados (Tab. 1).

São diversos os dados resultantes de modelos experimentalmente baseados na meia-vida de distintas biomoléculas que compõe os tecidos moles dependente da temperatura e, portanto, da vida útil esperada para essas biomoléculas em condições ótimas de preservação. Por outro lado, é necessário considerar que os fósseis com possíveis tecidos moles não mineralizados são preservados em camadas sedimentares que não experimentam altas temperaturas. Em geral, os estudos acima indicam que é previsto atualmente um curto intervalo temporal para biomoléculas informativas $( \pm$ 1 Ma para proteínas e \pm 100 mil anos para DNA; Bailleul et al., 2020).

Porém, existem relatos, por exemplo, de identificação de DNA original que superaram esses limites temporais de sobrevivência esperada para esse tipo de biomoléculas (Willerslev et al., 2007, Lindqvist, 2010), sugerindo que os modelos atuais seriam inadequados ou estariam incompletos (San Antonio et al., 2011) por que, em parte, não 
Tabela 1. Sobrevivência esperada de biomoléculas a diferentes temperaturas

\begin{tabular}{|c|c|c|}
\hline $\begin{array}{l}\text { Temperatura } \\
\text { média anual } \\
\left({ }^{\circ} \mathrm{C}\right)\end{array}$ & $\begin{array}{l}\text { Meia-vida } \\
\text { (anos) }\end{array}$ & Referências \\
\hline \multicolumn{3}{|c|}{ Proteína } \\
\hline $10^{\circ}$ & 1.000 .000 & Collins et al. (1995) \\
\hline \multirow[t]{2}{*}{$20^{\circ}$} & 2.000 & Buckley et al. (2008) \\
\hline & $100.000-1.000 .000$ & Bada et al. (1999) \\
\hline $7,5^{\circ}$ & 130.000 & Buckley et al. (2008) \\
\hline $10^{\circ}$ & $200.000-900.000$ & Buckley et al. (2011) \\
\hline \multirow[t]{2}{*}{$20^{\circ}$} & 580.000 & Nielsen-Marsh (2002) \\
\hline & 1.000 .000 & Asara et al. (2007) \\
\hline $0^{\circ}$ & 2.700 .000 & Nielsen-Marsh (2002) \\
\hline $10^{\circ}$ & 7.500 .000 & Nielsen-Marsh (2002) \\
\hline \multicolumn{3}{|c|}{ DNA } \\
\hline & 10.000 & Sykes (1991) \\
\hline \multirow[t]{2}{*}{$10^{\circ}$} & 17.500 & Smith et al. (2001) \\
\hline & 100.000 & $\begin{array}{c}\text { Schweitzer \&Wittmeyer } \\
(2006)\end{array}$ \\
\hline \multirow[t]{2}{*}{ menos $5^{\circ}$} & $158.000-6.800 .000$ & Allentoft et al. (2012) \\
\hline & $450.000-800.000$ & Willerslev et al. (2007) \\
\hline $10^{\circ}$ & 700.000 & Orlando et al. (2013) \\
\hline $0^{\circ}$ & 2.400 .000 & Allentoft et al. (2012) \\
\hline
\end{tabular}

por esteiras microbianas.

Acredita-se que tal resistência em aceitar tecidos moles originais se deva ao fato de as idades das amostras estarem muito além dos limites teóricos propostos para a sobrevivência esperada de moléculas orgânicas, e, portanto, terem de ser extrapoladas a partir de modelos de cinética teórica e experimentos de decaimento físico-químicos.

\section{Hipóteses de preservação de biomoléculas e Perspectivas futuras}

Muitas propostas têm sido desenvolvidas a fim de explicar essa aparente contradição, entre o limite máximo esperado de sobrevivência para distintas biomoléculas que compõem os tecidos moles descrito na literatura, e as dezenas de descobertas dessas biomoléculas originais que têm

considerariam as moléculas em seu estado nativo (ou seja, dobradas, compactadas, reticuladas ou, no caso dos ossos, estabilizados por associação mineral (Collins et al., 2000).

Por outro lado, algumas das previsões foram bem generosas, tal como no caso de Buckley et al. (2008) que utilizaram como variável a temperatura de $7,5^{\circ} \mathrm{C}$, a atual média anual de temperatura das regiões de Montana, onde o colágeno de dinossauro foi recuperado e sequenciado. O problema é que essas camadas de rochas sedimentares contendo dinossauros não avianos também continham flora e fauna que indicam temperaturas outrora muito mais altas (Johnson et al., 2002). Temperaturas mais baixas proporcionam menos reações químicas em relação ao decaimento e maior fidelidade na preservação de proteínas (Thomas \& Taylor, 2019).

A controvérsia continua e necessita de mais estudos a fim de validar ou não a robustez dessas previsões, uma vez que a deteç̧ão e o sequenciamento de possíveis proteínas antigas ainda permanecem limitados a 1,5 milhões de anos (Wadsworth \& Buckley, 2014, Cleland et al., 2015). Além de que, até o momento, não foi descartada por completa a possibilidade de essas estruturas identificadas como proteínas serem bioassinaturas produzidas sido observadas no registro fóssil.

Pesquisadores têm oferecido alguns cenários hipotéticos a fim de explicar a preservação de tecidos moles não mineralizados ao longo de dezenas de milhões de anos de reações geoquímicas que deveriam ter obliterado toda a bioquímica original. A Tabela 2 apresenta os possíveis dispositivos que funcionariam como mecanismo de preservação de biomoléculas originais.

Além desses, existem outros dispositivos propostos, tais como mineralização diagenética precoce ou substituição autigênica (Briggs et al., 1993, Zhu et al., 2005, Trinajstic et al., 2007), sulfurização (Mcnamara et al., 2006, Mcnamara et al., 2010) e outros (Briggs, 2003, Butterfield, 2003, Butterfield et al., 2007), mas, conforme afirmam Schweitzer e colaboradores, "poucos desses dispositivos de preservação foram testados experimentalmente" (2014, p.1).

Atualmente, grupos de pesquisa seguem analisando a paleoproteômica de dinossauros e outros fósseis mesozoicos e confirmando que esses fósseis podem realmente preservar as células proteicas originais (Schweitzer et al., 2009, Boatman et al., 2019, Bailleul et al., 2020). No entanto, ainda hoje inexistem mecanismos rigorosos e testáveis para explicar razoavelmente a potencial transformação 
Tabela 2. Principais dispositivos propostos para explicação da presença genuína (ou não) de tecidos moles não mineralizados em fósseis de dinossauros não avianos. Fonte: adaptado de Thomas (2019)

\begin{tabular}{|c|c|c|}
\hline Dispositivos de preservação & Proposto por & Questionado por \\
\hline $\begin{array}{c}\text { Contaminação moderna por biofilme } \\
\text { bacteriano }\end{array}$ & $\begin{array}{l}\text { Briggs et al. (1997) } \\
\text { Briggs (2003) } \\
\text { Kaye et al. (2008) } \\
\text { Raff et al. (2008) } \\
\text { Saitta et al. (2019) }\end{array}$ & $\begin{array}{c}\text { Schweitzer et al. (2009) } \\
\text { Schweitzer et al. (2013) } \\
\text { Armitage \& Anderson (2013) } \\
\text { Cleland et al. (2015) } \\
\text { Schweitzer et al. (2016) }\end{array}$ \\
\hline Adesão biomineral & $\begin{array}{l}\text { Collins et al. (2000) } \\
\text { San Antonio et al. (2011) }\end{array}$ & $\begin{array}{l}\text { Buckley et al. }(2008)^{\star} \\
\text { Thomas (2018) } \\
\text { Thomas \& Taylor (2019) }\end{array}$ \\
\hline Modelo de adsorção mineral de argila & Edwards et al. (2011) & Thomas (2013) \\
\hline Modelo de preservação de ferro & Schweitzer et al. (2014) & $\begin{array}{c}\text { Armitage \& Anderson (2014) } \\
\text { DeMasa \& Boudreaux (2015); } \\
\text { Anderson (2016) }\end{array}$ \\
\hline $\begin{array}{l}\text { Resíduos modernos na contaminação } \\
\text { por instrumentos }\end{array}$ & Buckley et al. (2017) & $\begin{array}{l}\text { Wiemann et al. (2018) } \\
\text { Thomas \& Taylor (2019) }\end{array}$ \\
\hline Modelo da "tostada" $\star \star$ & Wiemann et al. (2018) & $?$ \\
\hline
\end{tabular}

Obs.: * Buckley et al refutaram indiretamente a adesão biomineral antes de sua publicação em 2011, já tendo medido a taxa de decaimento do colágeno ósseo com adesão biomineral incluída. ** Deu-se o nome de "tostada" devido a uma analogia usada em uma matéria publicada pela Universidade Yale, na qual comparou o modelo de preservação recentemente descrito com as mudanças de cor que acontecem quando a torrada queima (processo de glicoxidação e lipoxidação).

e estabilização da matéria orgânica de dinossauros não avianos por meio da diagênese ao longo de dezenas de milhões de anos (Boatman et al., 2019).

\section{Considerações em aberto}

Apesar da raridade esperada para diferentes biomoléculas que compõem os tecidos moles não mineralizados em fósseis de dinossauros não avianos, esta pesquisa apresentou uma revisão da literatura disponível que objetiva nortear pesquisas mais amplas, representando quase metade das buscas por descritores de biomoléculas já levantadas para todos os demais táxons de animais e vegetais fósseis, o que sugere que os tecidos moles de fato são originais e tais achados não são fenômenos isolados.

Ainda assim, acredita-se que a frequência é subnotificada devido à atual resistência em aceitar os achados como sendo de remanescentes orgânicos e da falta de recursos para a detecção. Portanto, possivelmente existam muito mais fósseis de tecidos moles não mineralizados que podem ser recuperados e que anteriormente não haviam sido considerados. Assim como para outros táxons, também foi observado neste estudo que as investigações morfológicas e moleculares indicam que tecidos moles não mineralizados em fósseis de dinossauros não avianos é geológica, geográfica e taxonomicamente abrangente nas rochas mesozoicas.
Com base nos resultados aqui apresentados é possível prever que, a partir do surgimento de novas tecnologias - minimamente invasivas, simples de uso, de baixo custo e com alta sensibilidade à detecção de diferentes componentes orgânicos -, os achados de tecidos moles não mineralizados em fósseis de dinossauros não avianos provavelmente será a norma e não a exceção.

\section{Referências}

Allentoft, M. E., Collins, M., Harker, D., Haile, J., Oskam, C. L., Hale, M. L., Campos, P. F., ..., \& Bunce, M. (2012). The half-life of DNA in bone: measuring decay kinetics in 158 dated fossils. Proc Biol Sci., 279(1748), 4724-33. doi: 10.1098/ rspb.2012.1745.

Alleon, J., Bernard, S., Le Guillou, C., Marin-Carbonne, J., Pont, S., Beyssac, O., McKeegan, K. D., \& Robert, F. (2016). Molecular preservation of $1.88 \mathrm{Ga}$ Gunflint organic microfossils as a function of temperature and mineralogy. Nat Commun., 7, 11977. doi: 10.1038/ncomms11977.

Alleon, J.,Bernard, S., Le Guillou, C., Daval, D., Skouri-Panet, F., Kuga, M., \&Robert, F. (2017). Organic molecular heterogeneities can withstand diagenesis. Sci. Rep., 7(1):1508. doi: 10.1038/ s41598-017-01612-8.

Allison, P. A., \& Briggs, D. E. G. (1993). Exceptional fossil record: Distribution of soft-tissue preserva-

\begin{tabular}{c|c|c|c|c|c}
\hline (C) Terrae Didat. & Campinas, SP & v.16 & $1-14$ & $\mathrm{e} 020028$ & 2020 \\
\hline \multicolumn{4}{|c|}{8}
\end{tabular}


tion through the Phanerozoic. Geology, 21(6), 527530. doi: 10.1130/0091-7613.

Allison, P.A. (1988). Konservat-Lagerstätten: cause and classification. Paleobiology, 14(4), 331-344. doi: 10.1017/S0094837300012082.

Anderson, G. S., \& Bell, L. S. (2016). Impact of Marine Submergence and Season on Faunal Colonization and Decomposition of Pig Carcasses in the Salish Sea. PLoS One, 11(3), e0149107. doi: 10.1371/ journal.pone.0149107.

Anderson, K. (2016). Dinosaur Tissue: A Biochemical Challenge to the Evolutionary Timescale. Answers in Depth.

Arbour, V. M., \& Evans, D. C. (2017). A new ankylosaurine dinosaur from the Judith River Formation of Montana, USA, based on an exceptional skeleton with soft tissue preservation. $R$ Soc Open Sci., 4(5), 161086. doi: 10.1098/rsos.161086.

Armitage, M. H. (2001). Scanning electron microscope study of mummified collagen fibers in fossil tyrannosaurus rex bone. Crs Q., 38(2), 61-66.

Armitage, M. H., \& Anderson, K. L. (2013). Soft sheets of fibrillar bone from a fossil of the supraorbital horn of the dinosaur Triceratops horridus. Acta Histochem., 115(6), 603-608. doi: 10.1016/j.acthis.2013.01.001.

Armitage, M. H., \& Anderson, K. L. (2014). Light and Electron Microscopic Study of Soft Bone Osteocytes From a Triceratops horridus Supraorbital Horn. Microscopy and Microanalysis, 20(Suppl. S3), 1274-1275. doi: 10.1017/S1431927614008101

Asara, J. M., Schweitzer, M. H., Freimark, L. M., Phillips, M., \& Cantley, L. C. (2007a). Protein sequences from mastodon and Tyrannosaurus rex revealed by mass spectrometry. Science, 316(5822), 280-285. doi: 10.1126/science.1137614.

Asara, J. M., Garavelli, J. S., Slatter, D. A., Schweitzer, M. H., Freimark, L. M., Phillips, M., \& Cantley, L. C.(2007b). Interpreting sequences from mastodon and T. Rex. Science, 317(5843), 1324-1325. doi: 10.1126/science.317.5843.1324.

Bada, J., Wang, X. S., \& Hamilton, H. (1999). Preservation of key biomolecules in the fossil record: current knowledge and future challenges. Philos Trans R Soc Lond B Biol Sci., 354(1379), 77-87. doi: 10.1098/rstb.1999.0361.

Bailleul, A. M., Zheng, W., Horner, J. R., Hall, B. K., Holliday, C. M., \& Schweitzer, M. H. (2020). Evidence of proteins, chromosomes and chemical markers of DNA in exceptionally preserved dinosaur cartilage. National Science Review, 0, 1-8. doi: 10.1093/nsr/nwz206.

Bailleul, A. M., O’Connor, J., \& Schweitzer, M. H. (2019). Dinosaur paleohistology: review, trends and new avenues of investigation. PeerJ, 7, e7764. doi: $10.7717 /$ peerj.7764.

Benton, M. J. (1998). Dinosaur fossils with soft parts.
Trends Ecol Evol., 13(8), 303-4. doi: 10.1016/s01695347(98)01420-7.

Bern, M., Phinney, B. S., \& Goldberg, D. (2009). Reanalysis of Tyrannosaurus rex Mass Spectra.J. Proteome Res., 8(9), 4328-4332. doi: 10.1021/pr900349r.

Bertazzo, S., Maidment, S. C., Kallepitis, C., Fearn, S., Stevens, M. M., \& Xie, H. N. (2015). Fibres and cellular structures preserved in 75-million-yearold dinosaur specimens. Nat Commun., 6,7352. doi: 10.1038/ncomms8352.

Boatman, E. M., Goodwin, M. B., Holman, H. N., Fakra, S., Zheng, W., Gronsky, R., \&Schweitzer, M. H. (2019). Mechanisms of soft tissue and protein preservation in Tyrannosaurus rex. Sci Rep., 9(1), 1-12. doi: 10.1038/s41598-019-51680-1.

Bobrovskiy, I., Hope, J. M., Ivantsov, A., Nettersheim, B. J., Hallmann, C., \& Brocks, J. J. (2018). Ancient steroids establish the Ediacaran fossil Dickinsonia as one of the earliest animals. Science, 361(6408), 1246-1249. doi: 10.1126/science.aat7228.

Brand, L. R., Hussey, M., \& Taylor, J. (2003a). Decay and Disarticulation of Small Vertebrates in Controlled Experiments. Journal of Taphonomy, 1(2), 69-95.

Brand, L. R., Hussey, M., \& Taylor, J. (2003b). Taphonomy of Freshwater Turtles: Decay and Disarticulation in Controlled Experiments. Journal of Taphonomy, 1(4), 233-245.

Briggs, D. E. G. (2003). The Role Of Decay And Mineralization In The Preservation Of SoftBodied Fossils. Annual Review of Earth and Planetary Sciences, 31, 275-301. doi: 10.1146/annurev. earth.31.100901.144746.

Briggs, D. E. G., Kear, A. J., Martill, D. M., \& Wilby, P. R. (1993). Phosphatization of soft-tissue in experiments and fossils. Journal of the Geological Society, 150, 1035-1038. doi: 10.1144/gsjgs.150.6.1035.

Briggs, D. E. G., Wilby, P. R., Pérez-Moreno, B.P., Sanz, J. L., \& Fregenal-Martínez, M. (1997). The mineralization of dinosaur soft tissue in the Lower Cretaceous of Las Hoyas, Spain. Journal of the Geological Society, 154(4), 587-588. doi: 10.1144/ gsjgs.154.4.0587.

Brown, C. M., Henderson, D. M., Vinther, J., Fletcher, I., Sistiaga, A., Herrera, J., \& Summons, R. E. (2017). An exceptionally preserved three-dimensional armored dinosaur reveals insights into coloration and cretaceous predator-prey dynamics. Curr Biol.,27(16), 2514-2521. doi: 10.1016/j. cub.2017.06.071.

Buckley, M., \& Collins, M.J. (2011). Collagen survival and its use for species identification in HoloceneLower Pleistocene bone fragments from British archaeological and paleontological sites. Antiqua, 1(1), e1. doi: 10.4081/antiqua.2011.e1.

Buckley, M., Walker, A., Ho, S. Y., Yang, Y., Smith, C., Ashton, P., Oates, J. T., ..., \& Collins, M. J. (2008).

\begin{tabular}{c|c|c|c|c|c|}
\hline (C) Terrae Didat. & Campinas, SP & v.16 & $1-14$ & $\mathrm{e} 020028$ & 2020 \\
\hline
\end{tabular}


Comment on "Protein sequences from mastodon and Tyrannosaurus rex revealed by mass spectrometry”. Science, 319(5859), 33c. doi: 10.1126/ science.1147046.

Buckley, M., Warwood, S., van Dongen, B., Kitchener, A. C., \&Manning, P. L. (2017). A fossil protein chimera; difficulties in discriminating dinosaur peptide sequences from modern cross-contamination. Proc Biol Sci., 284(1855), pii:20170544. doi: 10.1098/rspb.2017.0544.

Butterfield, N. J. (2003). Exceptional fossil preservation and the Cambrian explosion. Integr Comp Biol., 43(1), 166-177. doi: 10.1093/icb/43.1.166.

Butterfield, N. J., Balthasar, U., \& Wilson, L. A. (2007). Fossil diagenesis in the burgess shale. Palaeontology, 50(3), 537-543. doi: 10.1111/j.14754983.2007.00656.x

Carvalho, I. S. (2010). Paleontologia: conceitos e métodos. (3rd ed.). Rio de Janeiro, RJ: Interciência.

Chin, K., Eberth, D. A., Schweitzer, M. H., Rando, T. A., Sloboda, W. J., \& Horner, J. R. (2003). Remarkable preservation of undigested muscle tissue within a Late Cretaceous tyrannosaurid coprolite from Alberta, Canada. Palaios, 18(3), 286-94. doi: 10.1669/0883-1351(2003)018<0286:rpoumt $>2.0$ .co;2.

Cleland, T. P., Schroeter, E. R., Zamdborg, L., Zheng, W., Lee, J. E., Tran, J. C., Bern, M., ..., \& Schweitzer, M. H. (2015). Mass spectrometry and antibody-based characterization of blood vessels from Brachylophosaurus canadensis. J Proteome Res., 14(12), 5252-5262. doi: 10.1021/acs.jproteome.5b00675.

Cody, G. D., Gupta, N. S., Briggs, D. E. R., Kilcoyne, A. L. D., Summons, R. E., Kenig F., Plotnick, R. E., \& Scott, A. C. (2011). Molecular signature of chitin-protein complex in Paleozoic arthropods. Geology, 39(3), 255-258. doi: 10.1130/G31648.1.

Collins, M. J., Riley, M. S., Child, A. M., \&TurnerWalker, G. (1995). A basic mathematical simulation of the chemical degradation of ancient collagen. J Archaeol Sci., 22(2), 175-183. doi: 10.1006/ jasc.1995.0019.

Collins, M. J., Gernaey, A. M., Nielsen-Marsh, C. M., Vermeer, C., \& Westbroek, P. (2000). Slow rates of degradation of osteocalcin: green light for fossil bone protein? Geology, 28, 1139-1142. doi: 10.1130/0091-7613(2000)28<1139:SRODOO >2 .0.CO;2.

Collins, M. J., Nielsen-Marsh, C. M.,Hiller, J.,Smith, C. I., Roberts, J. P.,Prigodich, R. V.,Wess, T. J., ..., \&Turner-Walker, G. (2002). The survival of organic matter in bone: A review. Archaeometry, 44(3), 383-394. doi: 10.1111/1475-4754.t01-1-00071.

Davies, K. L. (1987). Duck-Bill dinosaurs (Hadrosauridae, Ornithischia) from the North Slope of Alaska. J Paleontol., 61(1), 198-200. doi: 10.1017/ S0022336000028341.
Davis, M. (2014). Census of dinosaur skin reveals lithology may not be the most important factor in increased preservation of hadrosaurid skin. Acta Palaeontol. Pol., 59(3), 601-605. doi: 10.4202/ app.2012.0077.

DeMasa, J. M., \& Boudreaux, E. (2015). Dinosaur Peptide Preservation and Degradation. Crs Q., 51(4), 268-285.

Dobberstein, R. C., et al. (2009). Archaeological collagen: why worry about collagen diagenesis? Archaeolog Anthropological Sci., 1(1), 31-42. doi: 10.1038/252063a0.

Edwards, N. P., Barden, H. E., van Dongen, B. E., Manning, P. L., Larson, P. L., Bergmann, U., Sellers, W. I., \& Wogelius, R. A. (2011). Infrared mapping resolves soft tissue preservation in 50 million year-old reptile skin. ProcBiolSci., 278(1722), 32093218. doi: 10.1098/rspb.2011.0135.

Edwards, N. P., Manning, P. L., \&Wogelius, R. A. (2014). Pigmentsthrough time. Pigment Cell Melanoma Res., 27(5), 684-5. doi: 10.1111/pcmr.12271.

Eglinton, G., \& Logan, G. A. (1991). Molecular preservation. Philos Trans $R$ Soc Lond B Biol Sci., 333(1268), 315-328. doi: 10.1098/rstb.1991.0081.

Ehrlich, H., Rigby, J. K., Botting, J. P., Tsurkan, M. V., Werner, C., Schwille, P., Petrášek, Z., ..., \& Geisler, T. (2013). Discovery of 505-million-year old chitin in the basal demosponge Vauxia gracilenta. Sci Rep., 3, 3497. doi: 10.1038/srep03497.

Elder, R. L., \& Smith, G. R. (1988). Fish taphonomy and environmental inference in paleolimnology. Palaeogeography, Palaeoclimatology, Palaeoecology, 62(14), 577-592. doi: 10.1016/0031-0182(88)90072-7.

Embery, G., Milner, A., Waddington, R. J., Hall, R. C., Langley, M. S., \& Milan, A. M. (2000). The Isolation and Detection of Non-Collagenous Proteins from the Compact Bone of the Dinosaur Iguanodon. Connect Tissue Res., 41(3), 249-59. doi: 10.3109/03008200009005293.

Fabbri, M., Wiemann, J., Manucci, F., \& Briggs, D. E. G. (2020). Three-dimensional soft tissue preservation revealed in the skin of a non-avian dinosaur. Palaeontology, 63(2), 185-193. doi: 10.1111/ pala. 12470 .

Fernandes, I. (2020). Processos de preservação de fósseis de vertebrados quaternários coletados em cavernas carbonáticas de Minas Gerais e Bahia. (Monografia de Graduação em Engenharia Geológica). Escola de Minas, Universidade Federal de Ouro Preto, Ouro Preto, MG.

Gobbo, S. R., \& Bertini, R. (2015). Tecidos moles (não resistentes): como se fossilizam? Terre Didatica, 10(1), 2-13. doi: 10.20396/td.v10i1.8637374.

Greshko, M. (2020). Hints of fossil DNA discovered in dinosaur skull. National Geographic. URL: https:// www.nationalgeographic.com/science/2020/03/ hints-of-dna-discovered-in-a-dinosaur-fossil/.

\begin{tabular}{c|c|c|c|c|c}
\hline (C) Terrae Didat. & Campinas, SP & v.16 & $1-14$ & $\mathrm{e} 020028$ & 2020 \\
\hline
\end{tabular}


Gurley, L. R., Valdez, J. G., Spall, W. D., Smith, B. F., \& Gillette, D. D. (1991). Proteins in the fossil bone of the dinosaur, Seismosaurus.J Protein Chem., 10(1), 75-90. doi: 10.1007/BF01024658.

International Commission on Stratigraphy, ICS. (v2020/01). International Chronostratigraphic Chart. IUGS. URL: http://www.stratigraphy.org/ICSchart/ ChronostratChart2020-01.jpg. Acesso: 09.05.2020.

Isaacs, W. A., Little, K., Currey, J. D., \& Tarlo, L. B. (1963). Collagen and a cellulose-like substance in fossil dentine and bone. Nature, 197, 192. doi: 10.1038/197192a0.

Johnson, K. R., Nichols, D. J., \& Hartman, J. H. (2002). Hell Creek Formation: A 2001 synthesis. In: Johnson, K. R., Nichols, D. J., \&Hartman, J. H. (Eds.). 2002. The Hell Creek formation and the cretaceous-tertiary boundary in the Northern Great Plains. Geol Soc Am Spec Pap., 361, 503-510. doi: 10.1130/0-8137-2361-2.503.

Kaye, T. G., Gaugler, G., \& Sawlowicz, Z. (2008). Dinosaurian soft tissues interpreted as bacterial biofilms. PLoS One. 2008; 3(7), e2808. doi: 10.1371/ journal.pone.0002808.

Kielan-Jaworowska, Z. (1966). Third (1965) PolishMongolian Palaeontological Expedition to the Gobi Desert and Western Mongolia. Bull. Acad. Pol. Sci., 14(4), 249-252.

Kleeman, E. (2006). Fresh Meat: T. rex Bone Yields Solft Tissue But No DNA. Discover magazine, 27(1), 37.

Lee, Y. C., Chiang, C. C., Huang, P. Y., Chung, C. Y., Huang, T. D., Wang, C. C., Chen, C. I., ...,\& Reisz, R. R. (2017). Evidence of preserved collagen in an early Jurassic sauropodomorph dinosaur revealed by synchrotron FTIR microspectroscopy. Nat Commun., 31(8), 14220. doi: 10.1038/ ncomms14220.

Liang, R., Lau, M. C. Y., Saitta, E. T., Garvin, Z. K., \& Onstott, T. C. (2020). Genome-centric resolution of novel microbial lineages in an excavated Centrosaurus dinosaur fossil bone from the Late Cretaceous of North America. Environmental Microbiome, 15, 8. doi: 10.1186/s40793-020-00355-w

Lindqvist, C., Schuster, S. C., Sun, Y., Talbot, S. L., Qi, J., Ratan, A., Tomsho, L. P., .., \& Wiig, O. (2010). Complete mitochondrial genome of a Pleistocene jawbone unveils the origin of polar bear. Proc Natl Acad Sci USA., 107(11), 6118-6123.doi: 10.1073/ pnas.0914266107.

Lingham-Soliar, T., \& Plodowski, G. (2010). The integument of Psittacosaurus from Liaoning Province, China: taphonomy, epidermal patterns and color of a ceratopsian dinosaur. Naturwissenschaften, 97(5), 479-486.doi: 10.1007/s00114-010-0661-3.

Manning, P. L., Morris, P. M., McMahon, A., Jones, E., Gize, A., Macquaker, J. H., Wolff, G., ..., \& Wogelius, R. A. (2009). Mineralized soft-tissue struc- ture and chemistry in a mummified hadrosaur from the Hell Creek Formation, North Dakota (USA). Proc Biol Sci., 276(1672), 3429-3437. doi: 10.1098/rspb.2009.0812.

Martill, D. M. (1991). Organically preserved dinosaur skin: taphonomic and biological implications. Modern Geology, 16, 61-68.

Martill, D. M., Batten, D. J., \& Loydell, D. K. (2000). A new specimen of the thyreophoran dinosaur cf. Scelidosaurus with soft tissue preservation. Palaeontology, 43(3), 549-559. doi: 10.1111/j.00310239.2000.00139.x.

McNamara, M. E., Orr, P. J., Kearns, S. L., Alcalá, L., Anadón, P., \& Peñalver-Mollá, E. (2006). Highfidelity organic preservation of bone marrow in ca 10 Ma amphibians. Geology, 34(8), 641-644. doi: 10.1130/G22526.1.

McNamara, M., Orr, P. J., Kearns, S. L., Alcalá, L., Anadón, P., \& Peñalver-Mollá, E. (2010). Organic preservation of fossil musculature with ultracellular detail. Proc Biol Sci., 277(1680), 423-427.doi: 10.1098/rspb.2009.1378.

McNamara, M. E., Zhang, F., Kearns, S. L., Orr, P. J., Toulouse, A., Foley, T., Hone, D. W. E., ..., \& Zhou, Z. (2018). Fossilized skin reveals coevolution with feathers and metabolism in feathered dinosaurs and early birds. Nat Commun., 9(1), 2072. doi: 10.1038/s41467-018-04443-x.

Miller, M. F. 2nd., \& Wyckoff, R. W. (1968). Proteins in dinosaur bones. Proc Natl Acad Sci U S A., 60(1), 176-178. doi: 10.1073/pnas.60.1.176.

Moczydłowska, M., Westall, F., \& Foucher, F. (2014). Microstructure and Biogeochemistry of the organically preserved ediacaran metazoan sabellidites. J Paleontol., 88(2), 224-239. doi: 10.1666/13003.

Moyer, A. E., Zheng, W., \& Schweitzer, M. H. (2016). Microscopic and immunohistochemical analyses of the claw of the nesting dinosaur, Citipati osmolskae. Proc Biol Sci., 283(1842), pii: 20161997. doi: 10.1098/rspb.2016.1997.

Muyzer, G., Sandberg, P., Knapen, M. H. J., Vermeer, C., Collins, M., \& Westbroek, P. (1992). Preservation of boné protein osteocalcin in dinosaurs. Geology, 20(10), 871-874. doi: 10.1130/0091-7613(1992)020<0871:POTBPO> 2.3. CO;2.

Nielsen-Marsh, C. (2002). Biomolecules in fossil remains: Multidisciplinary approach to endurance. The Biochemist, 24(3), 12-14. doi: 10.1042/ BIO02403012.

Organ, C. L., Schweitzer, M. H., Zheng, W., Freimark, L. M., Cantley, L. C., \& Asara, J. M. (2008). Molecular phylogenetics of mastodon and Tyrannosaurus rex. Science, 320(5875), 499. doi: 10.1126/ science. 1154284.

Orlando, L., Ginolhac, A., Zhang, G., Froese, D., Al- 
brechtsen, A., Stiller, M., Schubert, M., ... Willerslev, E. (2013). Recalibrating Equus evolution using the genome sequence of an early Middle Pleistocene horse. Nature, 499(7456), 74-78. doi: 10.1038/nature12323.

Ostrom, P. H., Macko, S. A., Engel, M. H., Silfer, J. A., \& Russell, D. (1990). Geochemical characterization of high molecular weight material isolated from late cretaceous fossils. Organic Geochemistry, 16(4-6), 1139-1144. doi: 10.1016/01466380(90)90149-T.

Ostrom, P. H., Macko, S. A., Engel, M. H., \& Russell, D. (1993). Assessment of trophic structure of Cretaceous communities based on stable nitrogen isotope analyses. Geology, 21(6), 491-494. doi: 10.1130/0091-7613(1993)021<0491:AOTSOC > 2.3.CO;2.

Parry, L. A., Smithwick, F., Nordén, K. K., Saitta, E. T., Lozano-Fernandez, J., Tanner, A. R. , Caron, J. B., ..., \& Vinther, J. (2018). Soft-Bodied Fossils Are Not Simply Rotten Carcasses - Toward a Holistic Understanding of Exceptional Fossil Preservation: Exceptional Fossil Preservation Is Complex and Involves the Interplay of Numerous Biological and Geological Processes. Bioessays, 40(1), 1700167. doi: 10.1002/bies.201700167.

Pawlicki, R., Dkorbel, A., \& Kubiak, H. (1966). Cells, collagen fibrils and vessels in dinosaur bone. $\mathrm{Na}$ ture, 211(5049), 655-657. doi: 10.1038/211655a0.

Pawlicki, R., \& Nowogrodzka-Zagorska, M. (1998). Blood vessels and red blood cells preserved in dinosaur bones. Ann Anat., 180(1), 73-77. doi: 10.1016/s0940-9602(98)80140-4.

Pawlicki, R. (1995). Histochemical demonstration of DNA in osteocytes from dinosaur bones. Folia Histochem Cytobiol., 33(3), 183-186.

Pawlicki, R. (1977). Histochemical reactions for mucopolysaccharides in the dinosaur bone. Studies on Epon- and methacrylate-embedded semithin sections as well as on isolated osteocytes and ground sections of bone. Acta Histochem., 58(1), 75-8. doi: 10.1016/S0065-1281(77)80110-4.

Pawlicki, R. (1985). Metabolic pathways of the fossil dinosaur bones. Part V. Morphological differentiation of osteocyte lacunae and boné canaliculi and their significance in the system of extracellular communication. Folia HistochemCytobiol., 23(3), 165-174.

Pevzner, P. A., Kim, S., \& Ng, J. (2008). Comment on "Protein sequences from mastodon and Tyrannosaurus rex revealed by mass spectrometry". Science, 321(5892), 1040. doi: 10.1126/science.1155006.

Raff, E. C., Schollaert, K. L., Nelson, D. E., Donoghue, P. C., Thomas, C. W., Turner, F. R., Stein, B. D., ..., \& Raff, R. A. (2008). Embryo fossilizaiton is a biological process mediated by microbial biofilm. Proc. Natl Acad. Sci. USA, 105(49), 19360-5. doi: 10.1073/pnas.0810106105.

Reisz, R. R., Huang, T. D., Roberts, E. M., Peng, S., Sullivan, C., Stein, K., LeBlanc, A. R., ..., \& Zhong, S. (2013). Embryology of Early Jurassic dinosaur from China with evidence of preserved organic remains. Nature, 496(7444), 210-214. doi: 10.1038/nature11978.

Saitta, E. T., Liang, R., Lau, M. C., Brown, C. M., Longrich, N. R., Kaye, T. G., Novak, B. J., ..., \& Onstott, T. (2019). Cretaceous dinosaur bone contains recent organic material and provides an environment conducive to microbial communities. eLife, 8, e46205. doi: 10.7554/eLife.46205.

San Antonio, J. D., Schweitzer, M. H., Jensen, S. T., Kalluri, R., Buckley, M., \& Orgel, J. P. (2011). Dinosaur peptides suggest mechanisms of protein survival. PLoS One, 6(6), e20381. doi: 10.1371/ journal.pone.0020381.

Schroeter, E. R., DeHart, C. J., Cleland, T. P., Zheng, W., Thomas, P. M., Kelleher, N. L., Bern, M., \& Schweitzer, M. H. (2017). Expansion for the Brachylophosaurus canadensis collagen I sequence and additional evidence of the preservation of cretaceous protein. J Proteome Res., 16(2), 920-932. doi: 10.1021/acs.jproteome.6b00873.

Schweitzer, M. H., Marshall, M., Carron, K., Bohle, D. S., Busse, S. C., Arnold, E. V., Barnard, D., ..., \&Starkey, J. R. (1997a). Heme compounds in dinosaur trabecular bone. Proc Natl Acad Sci U S A, 94(12), 6291-6296. doi: 10.1073/pnas.94.12.6291.

Schweitzer, M. H., Johnson, C., Zocco, T. G., Horner, J. R., \& Starkey, J. R. (1997b). Preservation of biomolecules in cancellous bone of Tyrannosaurus rex. J. Vertebr. Paleontol., 17(2), 349-359. doi: 10.1080/02724634.1997.10010979.

Schweitzer, M. H., \& Horner, J. R. (1999). Intravascular microstructures in trabecular bone tissues of Tyrannosaurus rex. Ann. Paléontol., 85(3), 179-192. doi: 10.1016/S0753-3969(99)80013-5.

Schweitzer, M. H., Watt, J. A., Avci, R., Knapp, L., Chiappe, L., Norell, M., \& Marshall, M. (1999). Beta-keratin specific immunological reactivity in feather-like structures of the cretaceous alvarezsaurid, Shuvunia deserti. J Exp Zool., 285(2), 146-157. doi: 10.1002/(sici)1097010x(19990815)285:2<146::aid-jez7>3.0.co;2-a.

Schweitzer, M. H., Wittmeyer, J. L., Horner, J. R., \& Toporski, J. K. (2005a). Soft-tissue vessels and cellular preservation in Tyrannosaurus rex. Science, 307(5717), 1952-1955. doi: 10.1126/science.1108397.

Schweitzer, M. H., Chiappe, L., Garrido, A. C., Lowenstein, J. M., \& Pincus, S. H. (2005b). Molecular preservation in late cretaceous sauropod dinosaur eggshells. Proc Biol Sci., 272(1565), 775-784. doi: 10.1098/rspb.2004.2876.

Schweitzer, M. H., \&Wittmeyer,J. L. (2006). Dinosau- 
rian soft tissue taphonomy and implications. In: AAAS Annual meeting, Abstracts with Programs, St. Louis, Missouri, USA, 16-20 Feb.

Schweitzer, M. H., Suo, Z., Avci, R., Asara, J. M., Allen, M. A., Arce, F. T., \& Horner, J. R. (2007a). Analyses of soft tissue from Tyrannosaurus rex suggest the presence of protein. Science, 316(5822), 277-280. doi: 10.1126/science.1138709.

Schweitzer, M. H., Wittmeyer, J. L., \& Horner, J. R. (2007b). Soft tissue and cellular preservation in vertebrate skeletal elements from the Cretaceous to the present. Proc Biol Sci., 274(1607), 183-197. doi: 10.1098/rspb.2006.3705.

Schweitzer, M. H., Zheng, W., Organ, C. L., Avci, R., Suo, Z., Freimark, L. M., Lebleu, V. S., ..., \& Asara, J. M. (2009). Biomolecular characterization and protein sequences of the Campanian hadrosaur B. canadensis. Science, 324(5927), 626-631. doi: 10.1126/science. 1165069.

Schweitzer, M. H. (2011). Soft tissue preservation in terrestrial Mesozoic vertebrates. Annu. Rev. Earth Planet. Sci. 2011; 39, 187-216. doi: 10.1146/annurev-earth-040610-133502.

Schweitzer, M. H., Zheng, W., Cleland, T. P., \& Bern, M. (2013). Molecular analyses of dinosaur osteocytes support the presence of endogenous molecules. Bone, 52(1), 414-23. doi: 10.1016/j. bone.2012.10.010.

Schweitzer, M. H., Zheng, W., Cleland, T. P., Goodwin, M. B., Boatman, E., Theil, E., Marcus, M. A., \& Fakra, S. C. (2014). A role for iron and oxygen chemistry in preserving soft tissues, cells and molecules from deep time. Proc Biol Sci., 281(1775), 20132741. doi: 10.1098/rspb.2013.2741.

Schweitzer, M. H., Moyer, A. E., \& Zheng, W. (2016). Testing the Hypothesis of Biofilm as a Source for Soft Tissue and Cell-Like Structures Preserved in Dinosaur Bone. PLoS One, 11(2), e0150238. doi: 10.1371/journal.pone.0150238.

Schweitzer, M. H., Schroeter, E. R., Cleland, T. P., \& Zheng, W. (2019). Paleoproteomics of Mesozoic Dinosaurs and Other Mesozoic Fossils. Proteomics, 19(16), 1800251.doi: 10.1002/pmic.201800251.

Smith, C. I., Chamberlain, A. T., Riley, M. S., Cooper, A., Stringer, C. B., \& Collins, M. J. (2001). Neanderthal DNA: Not just old but old and cold? $\mathrm{Na}$ ture, 410(6830), 771-772.doi: 10.1038/35071177.

Sykes, B. (1991). The past comes alive. Nature, 352(6334), 381-2. doi: 10.1038/352381a0.

Thomas, B., \&Enyart, B. (2020). List of Biomaterial Fossil Papers. URL: https://docs.google.com/ spreadsheets/d/1eXtKzjWP2B1FMDVrsJ_992ITF K8H3LXfPFNM11l-Yiw/edit\# gid $=0$.

Thomas, B., \& Taylor, S. (2019). Proteomes of the past: the pursuit of proteins in Paleontology. Expert Review of Proteomics, 16(11-12), 881-895. doi: 10.1080/14789450.2019.1700114.
Thomas, B. (2013). A Review of Original Tissue Fossils and Their Age Implications. In: Proceedings of the Seventh International Conference. Pittsburgh, PA: Science Fellowship.

Thomas, B. (2018). Collagen remnants in ancient bone. (Tese de Doutorado). University of Liverpool, Liverpool, UK.

Towe, K. M., \& Urbanek, A. (1972). Collagen-like Structures in Ordovician Graptolite Periderm. Nature, 237, 443. doi: 10.1038 / 237443a0.

Trinajstic, K., Marshall, C., Long, J., \& Bifield, K. (2007). Exceptional preservation of nerve and muscle tissues in Late Devonian placoderm fish and their evolutionary implications. Biol Lett., 3(2), 197-200. doi: 10.1098/rsbl.2006.0604.

Ullmann, P. V., Pandya, S. H., \& Nellermoe, R. (2019). Patterns of soft tissue and cellular preservation in relation to fossil bone tissue structure and overburden depth at the standing rock hadrosaur site, maastrichtian hell creek formation, South Dakota, USA. Cretaceous Research, 99, 1-13. doi: 10.1016/j. cretres.2019.02.012.

van der Reest, A. J., \& Currie, P. J. (2020). Preservation frequency of tissue-like structures in vertebrate remains from the upper Campanian of Alberta: Dinosaur Park Formation. Cretaceous Research, 109, 104370. doi: 10.1016/j.cretres.2019.104370.

Vinther, J., Nicholls, R., Lautenschlager, S., Pittman, M., Kaye, T. G., Rayfield, E., Mayr, G., \& Cuthill, I. C. (2016). 3D camouflage in na ornithischian dinosaur. Curr Biol., 26(18), 2456-2462. doi: 10.1016/j.cub.2016.06.065.

Voss-Foucart, M. F. (1968). Paleoproteins of fossil shells of dinosaur eggs from upper cretaceous deposits of provence. Comp Biochem Physiol., 24(1), 31-36. doi: 10.1016/0010-406x(68)90954-7.

Xing, L., O’Connor, J. K., Schmitz, L., Chiappe, L. M., McKellar, R. C., Yi, Q., \& Li, G. (2020). Hummingbird-sized dinosaur from the Cretaceous period of Myanmar. Nature, 579, 245-249. doi: 10.1038/s41586-020-2068-4.

Wadsworth, C., \& Buckley, M. (2014). Proteome degradation in fossils: investigating the longevity of protein survival in ancient bone. Rapid Commun Mass Spectrom., 28(6), 605-15. doi: 10.1002/rcm.6821.

Wiemann, J., Yang, T. R., Sander, P. N., Schneider, M., Engeser, M., Kath-Schorr, S., Müller, C. E., \& Sander, P. M. (2017). Dinosaur origin of egg color: oviraptors laid blue-green eggs. PeerJ., 5, e3706. doi: 10.7717/peerj.3706.

Wiemann, J., Fabbri, M., Yang, T. R., Stein, K., Sander, P. M., Norell, M. A., \& Briggs, D. E. G. (2018). Fossilization transforms vertebrate hard tissue proteins into N-heterocyclic polymers. Nat Commun., 9(1), 4741.doi: 10.1038/s41467-018-07013-3.

Willerslev, E., Cappellini, E., Boomsma, W., Nielsen, R., Hebsgaard, M. B., Brand, T. B., \& Hofreiter, 
M. (2007). Ancient biomolecules from deep ice cores reveal a forested Southern Greenland. Science, 317(5834), 111-114. doi: 10.1126/science.1141758.

Wyckoff, R. W., \& Davidson, F. D. (1976). Pleistocene and dinosaur gelatins. Comp BiochemPhysiol B., 55(1), 95-97. doi: 10.1016/0305-0491(76)90179-6.

Yamagata, K., Nagai, K., Miyamoto, H., Anzai, M., Kato, H., Miyamoto, K., Kurosaka, ..., \& Iritani, A. (2019). Signs of biological activities of 28,000-yearold mammoth nuclei in mouse oocytes visualized by live-cell imaging. Sci Rep., 9, 4050. doi: 10.1038/ s41598-019-40546-1.

Zhang, F., Kearns, S. L., Orr, P. J., Benton, M. J., Zhou, Z., Johnson, D., Xu, X., \& Wang, X. (2010). Fossilized melanosomes and the colour of Cretaceous dinosaurs and birds. Nature, 463(7284), 10751078.doi: 10.1038/nature08740.

Zhu, M., Babcock, L. E., \& Steiner, M. (2005). Fossilization modes in the Chengjiang Lagerstatte (Cambrian of China): testing the roles of organic preservation and diageneticalteration in exceptional preservation. Palaeogeogr. Palaeoclimatol. Palaeoecol., 220(1-2), 31-46. doi: 10.1016/j.palaeo.2003.03.001.

Zimmer, C. (2008). Is dinosaur 'soft tissue' really slime? Science, 321(5889), 623. doi: 10.1126/ science.321.5889.623a.

Zylberberg, L., \& Laurin, M. (2011). Analysis of fossil bone organic matrix by transmission electron microscopy. Comptes Rendus Palevol., 10(5-6), 357366. doi: 10.1016/j.crpv.2011.04.004. 